\title{
Characteristics of ligature mark and throat skeleton fracture in deaths due to suicidal hanging: A retrospective study
}

\author{
Trishul O. Padole ${ }^{1}$, Sharad V. Kuchewar ${ }^{2 *}$, Manish B. Shrigiriwar ${ }^{3}$, S.H. Bhosle ${ }^{4}$ \\ ${ }^{1,2,4}$ Associate Professor, ${ }^{3}$ Professor, ${ }^{1,3,4}$ Dept. of Forensic Medicine, ${ }^{2}$ Dept. of Forensic Medicine, ${ }^{1,3,4}$ Shri Vasantrao Naik Government \\ Medical College, Yavatmal, Maharashtra, ${ }^{2}$ Govt. Medical College, Nagpur, Maharashtra, India
}

\begin{abstract}
Introduction: The typical findings of ligature mark on neck and throat skeleton fracture depends on multiple factors. The present study is an attempt to analyze relationship of these factors with ligature mark and throat skeleton fracture in suicidal deaths by hanging.

Materials and Methods: This retrospective study was conducted at the Department of Forensic Medicine of Shri Vasantrao Naik Government Medical College, Yavatmal, Maharashtra State (India). Total 147 suicide deaths due to hanging were autopsied by the Department during the period of 2017 to 2018. We used a pre-formed proforma to abstract data from files of these cases, the obtained information was tabulated and coded in to charts and analyzed.

Results: The male preponderance was observed $(84.34 \%)$ with age group of 21 to 30 years being most frequent. Nylon rope was used frequently among tough material by victim and Shela (long handkerchief) was most common soft ligature material. Tough ligature material frequently showed grooved ligature mark and soft showed shallow mark. More frequent throat skeleton fracture was observed with complete hanging, with age above 40 years and with tough ligature materials.

Conclusion: Definite relationship between type of ligature material and depth of ligature mark was observed. Also, degree of suspension was found to affect the level and direction of ligature mark on neck. There was a positive relation between throat skeleton fracture and the age of victim, type of ligature material and degree of suspension; whereas relationship with position of knot couldn't be concluded.
\end{abstract}

Keywords: Suicidal hanging, Tough material, Shela (long handkerchief), Throat skeleton fracture.

\section{Introduction}

In hanging, asphyxia is secondary to compression or constriction of the neckstructures by a noose or other constricting band tightened by the weight ofthe body ${ }^{1}$. Although deaths due to hanging are classified under asphyxial deaths, yet it is not the sole element involved. The frequency of hanging deaths, its complex mechanism and the frequent occurrence of discrepancies related to these deaths makes them common problem for both Forensic experts and Jurist. As hanging is a method used commonly for committing suicide, the every case of hanging brought for autopsy is considered suicidal until contrary is proved.

The ligature mark of hanging over neck appears as a furrow which initially has a pale yellow, parchment appearance, with a congested rim. With time, the furrow dries out and becomes dark brown ${ }^{1}$. The typical findings of hanging ligature mark in relation to its situation on neck, course, depth, width etc. depends on ligature material used and degree, duration and point of suspension. Depending upon degree of suspension, the hanging can be divided into two groups, complete and partial hanging. Complete hanging is a hanging in which the full body weight acts upon the ligature as constricting force. On the other hand partial hanging, some part of body touches the ground and partial weight of body acts upon the ligature as constricting force. ${ }^{2}$ The term 'typical hanging' is applied when the point of suspension is placed centrally over occiput. If the point of suspension is in any other position the term 'atypical hanging' is often used. ${ }^{3}$ Some authors divide point of suspension in four parts- front, back, right side and left side of neck. ${ }^{1}$

The characteristics of inner neck structure injuries indicates amount of violence towards the neck organs which facilitatedifferentiation of homicidal and suicidal manner of neck compression. The injury to the inner neck structures in hanging is deficient in many cases and the autopsy surgeon has to rely upon the ligature mark and the circumstantial evidence. However, the presence of inner neck injurycaused by hanging indicates intra-vitality of ligature mark on neck and help to establish the ante-mortem nature of hanging. ${ }^{4}$

The present study evaluate the characteristics of the external and internal neck findings of deaths due to hanging and focuses on the correlation of these findings with characteristics of ligature material, circumstances of hanging and the age of victim.

\section{Material and Methods}

The present retrospective study was conducted at Shri V. N. Government Medical College situated at Yavatmal city in Maharashtra state (India). This government teaching institute provides tertiary medical care for residents of Yavatmal district and neighboring territories. All the deaths due to unnatural causes took place in the institute, inthe city, referred from nearby villages and from the hospitals of the city were autopsied by the Department of Forensic Medicine of this institute.We reviewed all medico-legal autopsy

*Corresponding Author: Sharad V. Kuchewar, Dept. of Forensic Medicine, Govt. Medical College, Nagpur, Maharashtra, India

Email: skuchewar@gmail.com

http://doi.org/10.18231/J.IJFCM.2019.040 
record of period spanning from $1^{\text {st }}$ January 2017 to $31^{\text {st }}$ December 2018 retrospectively.

A total 147 cases of death due to hanging were autopsied by the Department during this period. The various epidemiological characteristicsof these hanging cases and the details of circumstances inclusive of history, type of ligature material, position of knot, type of suspension were studied from the inquest papers. And all the details of external and internal neck injuries present over the body of the victim were collected from the autopsy reports. The data of deaths due to hanging thus obtained were recorded in the proforma and coded into a chart, and they were analyzed.

\section{Results}

Among the 147 deaths by hanging autopsied over the period of 2-years, the manner of hanging in all the cases was suicidal with males were major contributors $(84.35 \%)$. The youngest victim of suicidal hanging was 13 years old and oldest was 95 years. The highest number of male as well as female cases was observed in the age group of 21 to 30 years. The second most frequent age group among males was 31 to 40 years, whereas among females it was 11 to 20 years (Fig. 1). In present study ligature material was known in all 147 cases. We divided the ligature materials into two broad groups. 1) Tough materials - e.g., rope (nylon \& cotton), electric wire, belt etc. 2) Soft materials - e.g. Odhani, Saree, Shella (long handkerchief), bed sheet, shirt etc. Tough materials contribute for $63.95 \%$ of ligature means used for hanging and remaining constitutes soft materials. The ligature material most commonly used to commit suicide by hanging was nylon rope $(58.50 \%)$ followed by long handkerchief $(11.56 \%)$ and Odhani $(8.16 \%)$. (Table 1$)$

We correlated the depth of the ligature mark with the type of ligature material used to commit suicidal hanging. In this regard, we noticed deep grooved ligature mark more frequently with tough materials $(87.23 \%)$ and most of the soft ligature materials showed shallow ligature mark (83.01\%) (Fig. 2). The degree of suspension of 45 victims could not be ascertained from all available record, 29 victims were in partial hanging position and 73 victims body was found completely suspended off the ground. Most commonly the ligature mark was observed above the level of thyroid cartilage. The ligature mark at the level of thyroid cartilage was found more frequently with partial hanging than complete hanging. Ligature mark was obliquely placed in all the cases. (Table 2)

In most of the cases of suicidal death by hanging, the throat skeleton was not fractured $(89.12 \%)$. Among the victims having throat skeleton fracture $(\mathrm{n}=16)$, isolated fracture of hyoid bone was more frequent $(n=12)$ as compared to fracture of thyroid cartilage $(n=04)$. No fracture of cricoids cartilage was noted in our study. Majority of hyoid bone fractures and thyroid cartilage fractures were observed with tough ligature material. The hyoid bone fracture was observed in 09 cases of complete suspension and only one case of partial suspension. Thyroid cartilage fracture was observed in 02 cases of complete suspension and one case each among partial hanging and unascertained type of suspension cases.

In present study, position of knot was divided into 4 groups namely anterior, right side, posterior and left side of neck, in relation to the projections of mastoid processes and angles of lower jaw as landmarks. The most common position found was posterior of neck (64 cases) \& least common was anterior of neck (15 cases). Throat skeleton fracture was more common with left side knot cases of hanging (23.53\%). Frequency of fracture of throat skeleton was more with increasing age of the victim. Victims of more than 40 years of age presented high incidence $(18.37 \%)$ of fracture of neck structures whereas this incidence was significantly less $(7.14 \%)$ in victims of age 40 years and below (Table 3).

\section{Discussion}

Hanging is leading method of committing suicide in India. The manner of death among the all the cases of hanging during the study period was suicidal $(100 \%)$. There was male preponderance $(84.35 \%)$ with highest number of cases observed in age group of 21 to 30 years. Similar finding of male preponderance were reported over years by Elfawal et al, ${ }^{5}$ Bowen BA, ${ }^{6}$ Batra et al, ${ }^{7}$ Azmak D, ${ }^{8}$ Davidson et al, ${ }^{9}$ Cooke et $\mathrm{al}^{10}$ and Simonsen J. ${ }^{11}$

Nylon rope was the most common ligature material $(53.01 \%)$ used for hanging. We divided all the ligature materials as tough or soft ligature material. Nylon rope was most common among tough ligature materials, whereas Shela (long handkerchief) was the most frequent among soft materials. Frequent use of nylon rope as ligature mean for committing hanging was probably because of nylon rope's common use for various domestic purposes and its low-cost and the farmer predominated area under consideration leads to its easy availability. The ligature means used by the victim for committing suicide by hanging may be anything available at his/ her hand during the thought of death, which includes any household article or belongings of the victim. This view is strengthened by our finding of Shela (long handkerchief) as the most common soft material used for hanging which is a popular Indian neck cloth material used by males, particularly in rural parts.

The composition of ligature material is an important factor affecting characteristics of external neck injury, specifically depth of the ligature mark. We observed that, the tough ligature materials commonly showed deep grooved ligature mark $(87.23 \%)$ and soft ligature materials show shallow ligature mark $(83.01 \%)$. Similar observation was reported by Elfawal et $\mathrm{al}^{5}$. The clarity and configuration of the ligature furrow over neck depend on the material used $^{1}$.

In our study, the ligature mark was present above the level of thyroid cartilage in majority of cases $(86.39 \%)$. The similar findings were reported by Davidson et $\mathrm{al}^{9}(93.34 \%)$, Sharma et $\mathrm{al}^{12}(84.62 \%)$ and Mukherjee $\mathrm{JB}^{13}(80 \%)$. Lower incidence of mark above the thyroid level was reported by Elfawal et $\mathrm{al}^{5}(65.57 \%)$ and Dixit et $\mathrm{al}^{14}(77 \%)$. Davidson et $\mathrm{al}^{9}$, Elfawal et $\mathrm{al}^{5}$ and Dixit et $\mathrm{al}^{14}$ have not reported 
differentiated level of mark at the level of thyroid cartilage or below it but they clubbed both as below the level. At the time of suspension, the noose typically slips above the larynx, catching under the $\operatorname{chin}^{1}$. The ligature mark at the level of thyroid cartilage was noted more with partial hanging. The partial hanging cases with forward inclination and less force giving tension over ligature material could be the reason for this finding. In our study, position of ligature mark was always oblique which is similar to the finding by Sharma et al ${ }^{12}(97.8 \%)$. The standard textbooks describe the obliquely placed ligature mark as an important differentiating point between hanging and ligature strangulation.

In the present retrospective study, an incidence of $8.16 \%$ was found for fracture of hyoid bone and of $2.72 \%$ for thyroid cartilage fracture. The varying percentages of throat skeleton fracture were reported by the researchers. ${ }^{4}$

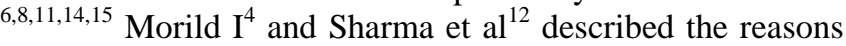
for variable frequency of fractures among different studies, which include lacking common method, proper handling and meticulous examination during autopsy. Other causative factors were different age composition of the study and whether the study is retrospective or prospective in which later gives high incidence of fractures. ${ }^{12}$

We evaluated relationship of throat skeleton fracture with the type of ligature material, degree of suspension, position of knot and age of the victim. In this study, about two third of victims had used tough materials as ligature means for hanging and remaining victims had used soft materials. Majority of Hyoid bone fractures and thyroid cartilage fractures were observed with tough ligature material. The finding of fracture throat skeleton common with tough ligature material such as electric cord or packing twine $(41 \%)$, Rope $(60 \%)$, waist belt $(60 \%)$ compared to soft materials such as linen $(00 \%)$ was reported by Simonsen J. ${ }^{11}$

$15.07 \%$ cases of complete hanging and $6.90 \%$ of partial hanging cases the throat skeleton was fractured. Though the number of partial hanging cases is low as compared to the complete hanging, this finding denotes that, throat skeleton fracture was more associated with complete suspension. Luke et $\mathrm{al}^{15}$ and MorildI $^{4}$ supported this finding of association of throat skeleton fracture with complete hanging. Similar finding with higher percentage $(56.66 \%$ in complete hanging \& $38 \%$ in partial hanging) was reported by Simonsen J. ${ }^{11}$ The higher percentage of fracture in completely suspended bodies resulted from rapid and forceful constriction of the neck, the ligature supporting the entire body weight and the more force acting on the throat skeleton.

During the study, the position of knot was classified as anterior, posterior or right or left side of neck. Boundaries of these regions taken into account for division purpose were projections of mastoid processes and angles of lower jaw same as used by Nikolic et al. ${ }^{17}$ Most common knot position observed in this study was posterior knot (43.54\%), which was also reported to be commonest by MorildI ${ }^{4}(35 \%)$ and Azmak $\mathrm{D}^{8}(66 \%)$, Nikolic et $\mathrm{al}^{17}(61.71 \%)$. There were different incidence of position of knot reported in previous studies, but all studies states that, anterior of neck is least common which is also true in the present study. The anterior part of neck is the least common site for knot in hanging cases probably because it is uncomfortable on the part of the victim to tie the knot on front with neck in hyper-extended position than tying the knot in other positions.

This study showed more frequent fracture throat skeleton with left side knot positions $(23.53 \%)$. Nikolic et $\mathrm{al}^{17}$ in his study reported that, $23.80 \%$ of right side knot hangings had hyoid bone/thyroid cartilage fracture compared to $18 \%$ of left side knot hangings. Charoonnate et $\mathrm{al}^{18}$ found hyoid bone and/or thyroid cartilage fractures more commonly in cases of knot position at left side and back of neck (33.33\%). Simonsen $\mathbf{J}^{11}$ concluded that the typical hangings were related to fractures showing $63 \%$ fractured throat skeleton. But, Morild $\mathrm{I}^{4}$ found $76 \%$ cases of laryngeal structure fracture with atypical hanging. There was no significant difference in fractures depending upon position of knot. This is in accordance with Nikolic et $\mathrm{al}^{17}$ and Charoonnate et al. ${ }^{18}$ They stated that there was no significant difference in hyoid bone horn fracture in relation to position of knot and other factors such as age, location of ligature and possible swing may play the important role.

Victims of more than 40 years of age presented high incidence $(18.37 \%)$ of fracture of throat skeleton whereas this incidence was significantly less $(7.14 \%)$ in victims of age 40 years and below. Luke et al, ${ }^{15}$ Davidson et $\mathrm{al}^{9}$, Betz et $\mathrm{al},{ }^{16}$ Morild $\mathrm{I}^{4}$ and Nikolic et $\mathrm{al}^{17}$ also reported high incidence of fracture with increasing age of the victims. All these authors described that, with advancing age the bones and cartilages of the neck get calcified, become rigid and brittle, thus more liable to fracture.

Table 1: Different types of ligature materials used by victims of Hanging $(n=147)$

\begin{tabular}{|c|c|c|}
\hline Type & Ligature material & Number \\
\hline \multirow{3}{*}{$\begin{array}{c}\text { Tough } \\
(\mathrm{n}=94)\end{array}$} & Nylon Rope & 86 \\
\cline { 2 - 3 } & Cotton Rope & 04 \\
\cline { 2 - 3 } & Belt & 03 \\
\cline { 2 - 3 } & Wire & 01 \\
\hline \multirow{4}{*}{$\begin{array}{c}\text { Soft } \\
(\mathrm{n}=53)\end{array}$} & Odhani & 12 \\
\cline { 2 - 3 } & Sharee & 03 \\
\cline { 2 - 3 } & Shela (Long handkerchief) & 17 \\
\cline { 2 - 3 } & Bedsheet & 04 \\
\cline { 2 - 3 } & Others & 17 \\
\hline
\end{tabular}


Table 2: Relation of type of suspension with characteristics of ligature mark

\begin{tabular}{|c|c|c|c|c|}
\hline \multicolumn{2}{|c|}{ Particulars of Ligature mark } & \multicolumn{3}{|c|}{ Type of Suspension } \\
\hline & & Complete( 73 cases) & Partial ( 29 cases) & Not known (45 cases) \\
\hline \multirow{3}{*}{$\begin{array}{c}\text { Level of mark } \\
\text { over neck }\end{array}$} & Above thyroid & 70 & 25 & 38 \\
\hline & At thyroid & 03 & 04 & 07 \\
\hline & Below thyroid & 00 & 00 & 00 \\
\hline \multirow[t]{2}{*}{ Direction } & Oblique & 73 & 29 & 45 \\
\hline & Horizontal & 00 & 00 & 00 \\
\hline
\end{tabular}

Table 3: Throat skeleton fracture in relation to characteristics of hanging deaths $(n=147)$

\begin{tabular}{|ll|c|c|c|}
\hline \multicolumn{2}{|c|}{ Characteristics of hanging } & $\begin{array}{c}\text { Hyoid fracture } \\
(\mathbf{n = 1 2})\end{array}$ & $\begin{array}{c}\text { Thyroid fracture } \\
(\mathbf{n = 0 4})\end{array}$ & $\begin{array}{c}\text { No fracture } \\
(\mathbf{n = 1 3 1})\end{array}$ \\
\hline 1. & Type of ligature & & & \\
\hline- & Tough & 10 & 03 & 51 \\
\hline- & Soft & 02 & 01 & 50 \\
\hline 2. & Type of Suspension & 09 & 02 & 62 \\
\hline- & Complete & 01 & 01 & 27 \\
\hline- & Partial & 02 & 01 & 42 \\
\hline- & Not known & & & 59 \\
\hline 3. & Position of knot & 04 & 01 & 14 \\
\hline- & Posterior & 00 & 01 & 32 \\
\hline- & Anterior & 03 & 00 & 13 \\
\hline- & Right side & 04 & 00 & 15 \\
\hline- & Left side & 01 & 00 & 91 \\
\hline- & Not known & & & 40 \\
\hline 1. & Age of victim & 06 & 01 & \\
\hline- & $<40$ years & 06 & 03 & \\
\hline- & $>40$ years & & & \\
\hline
\end{tabular}

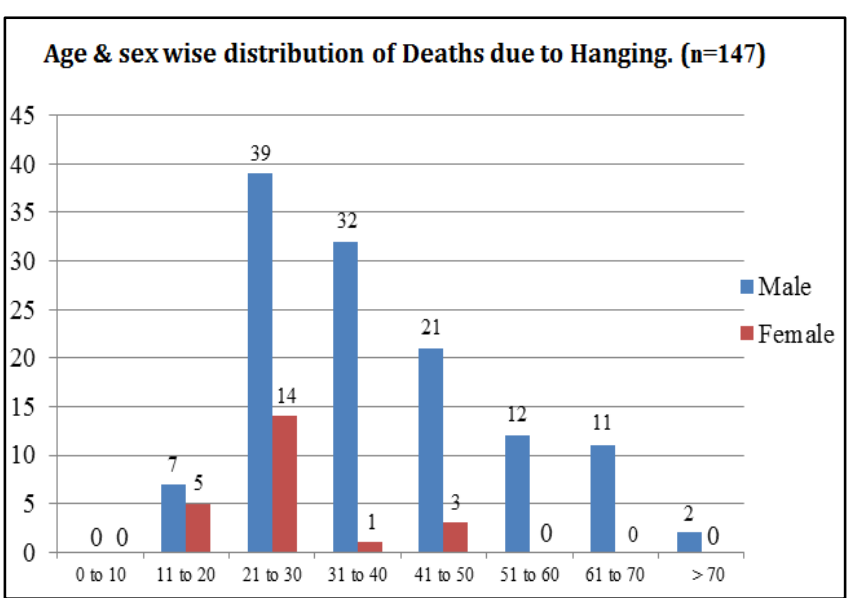

Fig. 1: Age and sex-wise distribution of deaths due to hanging $(n=147)$

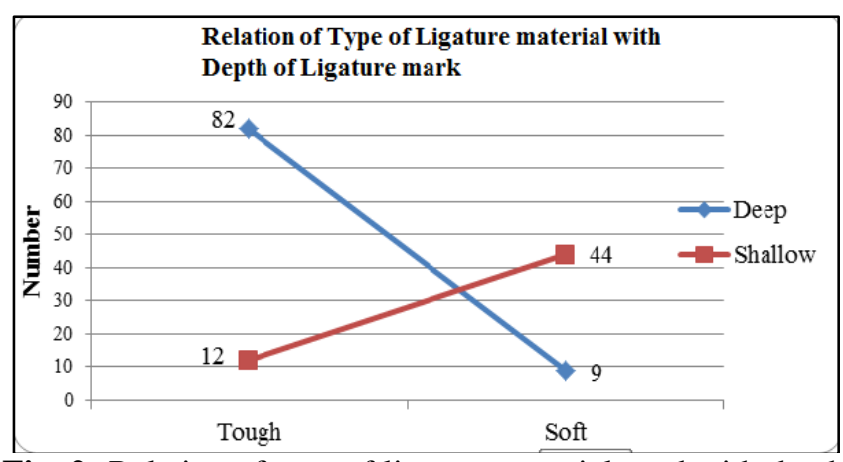

Fig. 2: Relation of type of ligature material used with depth of ligature mark. $(n=147)$

\section{Conclusion}

The victim of hanging uses easily available ligature materials to commit suicide like in present study the nylon rope among tough material and Shela (long Handkerchief) among soft material was frequently used ligature means. The peak incidence of mortality due to hanging is in age groups of 21 to 30 years. There was definite relationship between type of ligature material and depth of ligature mark. Also, degree of suspension was seems to affect the level and direction of ligature mark on neck. The more incidence of throat skeleton fracture is observed in current study with tough ligature materials, complete hanging \& with increasing age. The limitation of study may be apparent due to its retrospective nature. The multiple factors 
determine the outcome of suicidal hanging on neck structures which demand detailed prospective analysis.

\section{Acknowledgement}

None

\section{Conflict of Interest}

None.

\section{Source of Funding}

None.

\section{References}

1. DiMaio VJ, DiMaio D. Forensic Pathology. Second ed. Bocca Raton, Florida; CRC Press: 2001. p. 207-244.

2. Reddy KSN. The Essentials of Forensic Medicine\& Toxicology, Twenty ninth ed. Hyderabad, India, Om Sai graphics:2010. P. 306.

3. Sharma BR, Singh VP and Harish D. Neck structure injuries in hanging - comparing retrospective and prospective studies. J Med Sci Law 2005;45(4):321-30.

4. Morild I. Fractures of neck structures in suicidal hanging. Med Sci Law 1996; 36(1):80-4.

5. Elfawal MA, Awad OA. Death from hanging in the eastern province of Saudi Arabia. Med Sci Law 1994;34(4): 307-12.

6. Bowen BA. Hanging - a review. J Forensic Sci int 1982;20(3):247-9.

7. Batra AK, Dongre AP. A Preliminary Analysis of Medicolegal Autopsies Performed over Five years in a rural Health District of Maharashtra state of India. J Forensic Med Toxicol 2003;20(1):41-6.

8. Azmak D. Asphyxial deaths: a retrospective study and review of literature. Am J Forensic Med Pathol 2006;27(2):134-44
9. Davidson A, Marshall TK. Hanging in Northern Ireland-a survey. Med Sci Law 1986;26:23-8.

10. Cooke CT, Cadden GA, Margolius KA. Death by hanging in Western Australia. Pathol 1995;27(3):268-72.

11. Simonsen J. Patho-anatomic findings in neck structures in asphyxiation due to hanging: A survey of 80 cases. Forensic Sci Int 1988;38:83-91.

12. Sharma BR, Harish D, Singh VP, Sigh J. Ligature Mark on the neck: how Informative? J Indian Acad of Forensic Med 2005:27(1):10-5.

13. Mukharjee JB. Forensic Medicine and Toxicology edited by R. N. Karmakar, Third edition New Delhi; Arnold Associates, Delhi: 2007;571-617.

14. Dixit PG, Mohite PM, Ambade VN. Study of histopathological changes in thyroid, salivary gland and lymph nodes in hanging, $J$ Forensic Med and Toxicol 2001;18(2):1-4.

15. Luke JL, Reay DT, Eisele JW, Bonnell HJ. Correlation of circumstances with pathological findings in asphyxial deaths by hanging: a prospective study of 61 cases from Seattle, WA. J Forensic Sci 1985 Oct; 4: 1140-1147.

16. Betz P, Eisenmenger W. Frequency of throat-skeleton fractures in hanging. Am J Forensic Med Pathol 1996;17(3):191-3.

17. Nikolic S, Misic J, Atanasijevic T, Djokic V, Djonic D. Analysis of neck injuries in hanging. Am J Forensic Med Pathol 2003;24(2):179-82.

18. Charoonnate N, Narongchai P, Vongvaivet S. Fractures of the hyoid bone and thyroid cartilage in suicidal hanging. $J$ Med Assoc Thai 2010;93(10):1211-6.

How to cite this article: Padole TO, Kuchewar SV, Shrigiriwar MB, Bhosle SH. Characteristics of ligature mark and throat skeleton fracture in deaths due to suicidal hanging: A retrospective study. Indian J Forensic Community Med 2019;6(3):177-181 